\title{
RESEARCH
}

Open Access

\section{Continuous exposure of isoprenaline inhibits myoblast differentiation and fusion through PKA/ERK1/2-FOXO1 signaling pathway}

Shao-juan Chen ${ }^{1,2+}$, Jing Yue ${ }^{1 \dagger}$, Jing-Xuan Zhang ${ }^{3,5}$, Miao Jiang ${ }^{1}$, Tu-qiang Hư ${ }^{4}$, Wei-dong Leng ${ }^{2}$, Li Xiang ${ }^{1,3}$, Xin-yuan Li ${ }^{1}$, Lei Zhang ${ }^{1,5}$, Fei Zheng ${ }^{1}$, Ye Yuan ${ }^{1}$, Lin-yun Guo ${ }^{1,5}$, Ya-mu Pan', Yu-wen Yan ${ }^{1}$, Jia-ning Wang ${ }^{1,5}$, Shi-You Chen ${ }^{6}$ and Jun-ming Tang ${ }^{1,3,5^{*}}$

\begin{abstract}
Aim: The objective of this study is to determine if exuberant sympathetic nerve activity is involved in muscle satellite cell differentiation and myoblast fusion.

Methods and results: By using immunoassaying and western blot analyses, we found that $\beta 1$ and $\beta 2$-adrenergic receptors (AdR) were expressed in C2C12 cells. The differentiated satellite cells exhibited an increased expression of $\beta 2-A d R$, as compared with the proliferating cells. Continuous exposure of isoprenaline (ISO), a $\beta$-AdR agonist, delayed $\mathrm{C} 2 \mathrm{C} 12$ cell differentiation, and myoblast fusion in time- and dose-dependent manner. ISO also increased short myotube numbers while decreasing long myotube numbers, consistent with the greater reduction in $\mathrm{MyHC1}$, MyHC2a, and MyHC2x expression. Moreover, continuous exposure of ISO gradually decreased the ratio of PKA RI/RII, and PKA RI activator efficiently reversed the ISO effect on C2C12 cell differentiation and myoblast fusion while PKA inhibitor H-89 deteriorated the effects. Continuous single-dose ISO increased $\beta 1$-AdR expression in C2C12 cells. More importantly, the cells showed enhanced phospho-ERK1/2 levels, resulting in increasing phospho- $\beta 2$-AdR levels while decreasing $\beta 2$-AdR levels, and the specific effects could be abolished by ERK1/2 inhibitor. Furthermore, continuous exposure of ISO induced FOXO1 nuclear translocation and increased the levels of FOXO1 in nuclear extracts while reducing pAKT, p-p38MAPK, and pFOXO1 levels. Conversely, blockade of ERK1/2 signaling partially abrogated ISO effects on AKT, p38MAPK, and FOXO1signaling, which partially restored C2C12 cell differentiation and myoblast fusion, leading to an increase in the numbers of medium myotube along with the increased expression of MyHC1 and MyHC2a.
\end{abstract}

Conclusion: Continuous exposure of ISO impedes satellite cell differentiation and myoblast fusion, at least in part, through PKA-ERK1/2-FOXO1 signaling pathways, which were associated with the reduced $\beta 2-A d R$ and increased B1-AdR levels.

Keywords: Isoprenaline, Adrenergic receptor, Differentiation, Myoblast fusion, PKA, ERK1/2, FOXO1

\footnotetext{
*Correspondence: tangjm416@163.com

Shao-juan Chen and Jing Yue are co-first author.

'Department of Cardiology, and Institute of Clinical Medicine, Renmin Hospital, Hubei University of Medicine, Shiyan 442000, Hubei, People's Republic of China

${ }^{3}$ Department of Physiology, School of Basic Medical Sciences, Hubei University of Medicine, Shiyan 442000, Hubei, People's Republic of China Full list of author information is available at the end of the article
}

C The Author(s). 2019 Open Access This article is distributed under the terms of the Creative Commons Attribution 4.0 International License (http://creativecommons.org/licenses/by/4.0/), which permits unrestricted use, distribution, and reproduction in any medium, provided you give appropriate credit to the original author(s) and the source, provide a link to the Creative Commons license, and indicate if changes were made. The Creative Commons Public Domain Dedication waiver (http://creativecommons.org/publicdomain/zero/1.0/) applies to the data made available in this article, unless otherwise stated. 


\section{Introduction}

Muscular dystrophy (MD) is a destructive neuromuscular disease characterized by progressive muscle weakness, muscle atrophy, and cardiac dysfunction [1]. In addition to the primary muscular defects, another possible contributor to the generation of pathology in MD is the autonomic dysfunction [2]. Indeed, an autonomic imbalance has been observed in which sympathetic activity is increased while coupled with diminished parasympathetic activity, contributing to the development of dilated cardiomyopathy (DCM), ventricular arrhythmias, and sudden cardiac death in patients with Duchenne and Becker MD [1, 3]. In response to norepinephrine $(\mathrm{NE})$ and epinephrine (E) released by components of the sympathetic nerve system (SNS), activation of $\beta 1$ - and $\beta 2$-adrenergic receptors (AdRs), as a result of $\mathrm{NE}$ and $\mathrm{E}$ binding to specific AdRs, is the most important physiologic mechanism to acutely increase cardiac performance via positive inotropic, dromotropic, and chronotropic effects $[4,5]$. However, most studies have focused on the impact of autonomic dysfunction on cardiac performance and morphology in MD with little attention to its possible role in the development of skeletal myopathy.

Accumulated data have shown that activated $\beta$-AdR, a typical indication of excessive SNS, is involved in the development of essential hypertension and heart failure (HF) [4-6]. Indeed, the over-activated SNS exacerbates the HF with clinical features such as physical activity limitation, fatigue, and skeletal muscle atrophy [7]. It has been speculated that autonomic imbalance inhibits the anabolism of skeletal muscle, attributing to the reduced expression and sensitivity of $\beta 2$-AdR in skeletal muscle [8]. These results suggest that $\beta$-AdR is involved in MD.

Muscle-resident satellite cells contribute to muscle renewal and maintenance in accordance with physical demand and repair after disease or injury [9]. The regenerative capacity of satellite cells in myotonic dystrophy is constitutively impaired, causing loss of muscle fibers with disease progression and aging [10, 11]. Based on the involvement of autonomic nervous dysfunction in skeletal muscle atrophy, we hypothesize that the changes of $\beta$-AdR activities impair satellite cell differentiation and myoblast fusion, resulting in skeletal muscle atrophy. In this study, we used $\beta$-AdR agonist isoproterenol (ISO) to stimulate an abnormal activation of $\beta 1$-AdR and inactivation of $\beta 2$-AdR to uncover the possible relationship between satellite cells and muscle atrophy due to the over-activation of SNS.

\section{Method}

Reagents and chemicals

CPG 20712A was purchased from Tocris Bioscience. H 89 (S1582) was purchased from Selleckchem.
Isoprenaline (ISO, I5627), N6-Benzoyladenosine-3',5' -cyclic monophosphate sodium salt $\left(\mathrm{N}^{6}-\mathrm{Bz}-\mathrm{cAMP}, \mathrm{B} 4560\right)$, and PD98059 (P215) were purchased from Sigma-Aldrich and reconstituted in their corresponding vehicle according to the manufacturer's instructions.

\section{The culture and differentiation of $\mathrm{C} 2 \mathrm{C} 12$ cells}

The myoblast $\mathrm{C} 2 \mathrm{C} 12$ cells that were purchased from Cell bank of the Chinese Academy of Sciences were inoculated in $75-\mathrm{cm}^{2}$ culture dish and cultured with high glucose DMEM containing 10\% fetal bovine serum (FBS) at $37 \mathrm{C}$ and $5 \% \mathrm{CO}_{2}$. When cells confluence reached $70 \%$ to $80 \%$, the culture medium was replaced with high glucose DMEM containing 2\% horse serum (HS) to induce C2C12 cell differentiation. The $\mathrm{C} 2 \mathrm{C} 12$ cell differentiation into myotubes was observed every day under a microscope. The formation of myotubes from $\mathrm{C} 2 \mathrm{C} 12$ cells were detected by myotube markers at the 3rd, 5 th, and 8 th day of differentiation [12].

\section{ISO delivery method in vitro}

C2C12 cells cultured in high glucose DMEM containing $2 \% \mathrm{HS}$ at $70 \%$ confluence were exposed to ISO transiently or continuously. In brief, the transient ISO-delivery is to add ISO for only one time on the first day of the differentiation and then replace with fresh differentiation medium every day. The continuous exposure is to add the same dose of ISO each day when the differentiation medium is replaced. Different dosages of ISO (i.e., $10^{-8} \mathrm{M}, 10^{-7} \mathrm{M}$, $10^{-6} \mathrm{M}$, or $10^{-5} \mathrm{M}$ ) were also applied in the subsequent experiments. Myotube formation was analyzed 5-8 days after the ISO treatment.

\section{Adrenergic receptor assay}

C2C12 cells were inoculated to 24-well plates with $1.25 \times 10^{4}$ cells/well. The cells were cultured irregular medium for $24 \mathrm{~h}$ or in the differentiation medium for 6 days. Cells were then fixed with $4 \%$ polyoxymethylene for $15 \mathrm{~min}$ and washed with PBS for 3 times ( $5 \mathrm{~min} /$ time). Five percent goat serum and $0.3 \%$ Triton- 100 were used to block the nonspecific antigen for $30 \mathrm{~min}$. Subsequently, the primary antibodies including $\beta 1$ (ab3442)- and $\beta 2$ (ab36956)-adrenergic receptor (AdR, 1:100, Abcam) were added onto the corresponding wells and incubated overnight at $4{ }^{\circ} \mathrm{C}$. After washing with PBS 3 times for $15 \mathrm{~min}$, cells were incubated with corresponding fluorescent dye-labeled secondary antibodies (1:250) at room temperature for $2 \mathrm{~h}$. Cells were then observed and photographed under fluorescence microscope [13]. To quantitatively analyze the expression of adrenergic receptors in $\mathrm{C} 2 \mathrm{C} 12$ and differentiated cells, cell lysates were collected for western blot analyses 6 days after the culture or differentiation. 


\section{Immunofluorescence staining}

$\mathrm{C} 2 \mathrm{C} 12$ cells were treated similarly as in AdR assay above. Primary antibodies against MyHC (sc-20641, 1:150, Santa Cruze) and FOXO1 (SC-9808, 1:150, Santa Cruze) were added into the corresponding wells and incubated overnight at $4{ }^{\circ} \mathrm{C}$. After washing with PBS 3 times for $15 \mathrm{~min}$, cells were incubated with corresponding fluorescent dye-labeled secondary antibodies $(1: 250)$ at room temperature for $2 \mathrm{~h}$. DAPI (Molecular Probes) was used to stain nuclei. The corresponding images were observed and photographed under a fluorescence microscope [14].

\section{Myotube morphology}

Cells were stained for $\mathrm{MyHC}$ using $\mathrm{MyHC}$ polyclonal rabbit anti-mice antibody (sc-20,641, 1:150, Santa Cruze) followed by anti-rabbit TRITC or FITC-labeled secondary antibody (Jackson Lab, 1:400, USA). DAPI was used to stain nuclei. Myotube was defined as 3+ nucleuses within a cellular structure in order to rule out myoblast cells undergoing mitosis. The images of five locations including up, down, left, right sides, and center of each slide were photographed using an 80i Nikon fluorescent microscope (Nikon, Japan). A total of 30 images/group within six repeats were taken by using the same imaging parameters. Images were analyzed by two pathologists using Image J (Java) software (National Institutes of Health, USA) in a double-blind manner. Morphology was assessed by myotube length, number of myotube per view, and number of myoblast fusion (nuclei numbers as the indicator) per myotube [15-17]. In order to facilitate the description of myotube characteristics, the myotubes were divided into 3 types including short, medium, and long myotubes. Short myotube was defined as those shorter than $200 \mu \mathrm{m}$ with less than 5 myoblast fusions, and long myotubes were defined as those longer than $400 \mu \mathrm{m}$ with more than 10 myoblast fusion; medium myotube were those between the short and long myotubes.

\section{Quantitative RT-PCR}

Total RNA was extracted from $\mathrm{C} 2 \mathrm{C} 12$ cells using TRIzol reagents (Life Technologies) and transcribed into cDNA using the SuperScript II cDNA kit (Life Technologies). Quantitative PCR was performed using SYBR green PCR master mix (Applied Biosystems) in RotorGene 6000 Real-Time PCR System (Qiagen, Mannheim, Germany). The transcript levels of interested genes in the corresponding groups were compared after normalization to GAPDH levels [18]. The primers used are shown in Table 1.

\section{Western blot}

C2C12 cells were homogenized on ice in $0.1 \%$ Tween- 20 homogenization buffer containing protease inhibitors. Nuclear and cytosolic proteins in $\mathrm{C} 2 \mathrm{C} 12$ cells were isolated and collected using NE-PER Nuclear and Cytoplasmic Extraction Reagents by following the manufacturer's instruction $(78,835$, Thermo Scientific, USA). $20 \mu \mathrm{g}$ of proteins were resolved in 7 or $10 \%$ SDS-PAGE gel and transferred onto a polyvinylidene fluoride (PVDF) membrane (Millipore). After being blocked with $5 \%$ nonfat milk, the membrane was incubated with primary antibody (1:1000 dilution) for $90 \mathrm{~min}$ followed by incubation with horseradish peroxidase (HRP)-conjugated secondary antibodies (anti-rabbit IgG, anti-goat IgG, 1:10000; Santa Cruz). Protein expression was visualized by enhanced chemiluminescence reaction and measured by densitometry. The primary antibody used were as follows: $\alpha$-tubulin (T9026, 1:5000, Sigma), $\beta 1$-AdR (ab3442, 1:1000, Abcam), ß2-AdR (ab182136, 1:1000, Abcam), p- $\beta 2-A d R$ (PA5-36784, 1:500, Thermo), PKA $\alpha$ cat (sc-28315, 1:500, Santa Cruze), PKAy cat (sc-514,087, 1:500, Santa Cruze), PKA $\alpha / \beta / \Upsilon_{\text {cat }}$ (sc-365615, 1:500, Santa Cruze), PKA RI $\alpha$ (sc-136231, 1:500, Santa Cruze), PKA Ri $\beta$ (sc-100414, 1:500, Santa Cruze), PKA RII $\alpha$ (sc-136262, 1:500, Santa Cruze), PKA RII (sc-376778, 1:500, Santa Cruze), AKT (\#9272 s, 1:500, Cell Signaling),

Table 1 The sequences of primers of $\mathrm{QPCR}$

\begin{tabular}{|c|c|c|}
\hline Gene & Forward & Reverse \\
\hline MyoG & 5'-GAGACATCCCCCTATTTCTACCA-3' & 5'-GCTCAGTCCGCTCATAGCC-3' \\
\hline MyoD1 & 5'-CCACTCCGGGACATAGACTTG-3' & 5'-AAAAGCGCAGGTCTGGTGAG-3' \\
\hline $\mathrm{MyHC1}$ & 5'-CAAGCAGCAGTTGGATGAGCGACT-3' & 5'-TCCTCCAGCTCCTCGATGCGT-3' \\
\hline $\mathrm{MyHC2a}$ & 5'-AGAGGACGACTGCAGACCGAAT-3' & 5'-GAGTGAATGCTTGCTTCCCCCTTG-3' \\
\hline MyHC2b & 5'-ACGCTTGCACACAGAGTCAG-3' & 5'-CTTGGACTCTTCCTCTAGCTGCC-3' \\
\hline MyHC2x & 5'-ACCAAGGAGGAGGAACAGCAGC-3' & 5'-GAATGCCTGTTTGCCCCTGGAG-3' \\
\hline GAPDH & 5'-ATGACTCCACTCACGGCAAA-3' & 5'-ATGATGACCCTITTGGCTCC-3' \\
\hline
\end{tabular}

qPCRs were performed to identify the traits of satellite cell differentiation and muscle fibers by using the specific primers of satellite cell differentiation markers including MyoD and MyoG, type I muscle fiber makers like MyHC1, and type II muscle fiber makers such as MyHC2a, MyHC2b, and MyHC2X. GAPDH as an internal control 
pAKT (\#4058 s, 1:500, Cell Signaling), extracellular signal-regulated kinase (ERK1/2, SC-94, SC-154, 1:500, Cell Signaling), $p$ ERK1/2(4370s, 1:500, Cell Signaling), mitogen-activated protein kinase (p38MAPK, \#9211, 1:500, Cell Signaling), $p$-p38MAPK (sc-7973, 1:500, Cell Signaling), PKC $\alpha$ (sc-8393,1:500,Santa Cruze), $p$ PKC $\alpha$ (sc-12356, 1:500, Santa Cruze), FOXO1 (sc-9808, 1:500, Santa Cruze), $p$ FOXO1(sc-101681, 1:150, Santa Cruze), Histone H3(ab6002, 1:500, ABCAM), MuRF1 (ab77577, 1:500, Abcam), MyHC (sc-20641, sc-376157, 1:500, Santa Cruze), and MyoG (sc-12732, 1:500, Santa Cruze), respectively. The semi-quantitative analysis was done by using the Image $\mathrm{J}$ software to measure the gray value [19].

\section{Statistical analysis}

Data shown are mean \pm SD. Statistical significance between two groups was determined by paired or unpaired Student's $t$ test. Results for more than two experimental groups were evaluated by one-way ANOVA to specify differences between groups. $P<$ 0.05 was considered significant.

\section{Results}

Continuous stimulation with ISO inhibited $\mathrm{C} 2 \mathrm{C} 12$ cell differentiation and myotube formation

To explore the potential role of ISO in $\mathrm{C} 2 \mathrm{C} 12$ cell differentiation, myotube formation following $\mathrm{C} 2 \mathrm{C} 12$ cell differentiation with $2 \%$ HS-DMEM was firstly observed under a microscope, and the differentiated $\mathrm{C} 2 \mathrm{C} 12$ cells showed myotube formation characterized by multinucleated myoblast fusion in a time-dependent manner. During the first and second day of differentiation, $\mathrm{C} 2 \mathrm{C} 12$ cells did not show obvious myotube formation. Starting from the third day, $\mathrm{C} 2 \mathrm{C} 12$ cells began to form a few short myotubes. On the fourth day, the differentiated cells started to form long myotubes. The number of myoblast fusion in myotubes increased gradually and reached the peak on the 6th day (Additional file 1: Figure S1A). Meanwhile, the MyHC expression increased progressively and reached the peak at the 6th day as well (Additional file 1: Figure S1A-C).

To explore the effect of ISO on C2C12 cell differentiation, myotube morphology was observed by immunostaining of MyHC. As shown in Additional file 1: Figure $\mathrm{S} 1 \mathrm{D}$, continuous exposure of ISO to $\mathrm{C} 2 \mathrm{C} 12$ cells shortened the MyHC-positive myotube and the myoblast

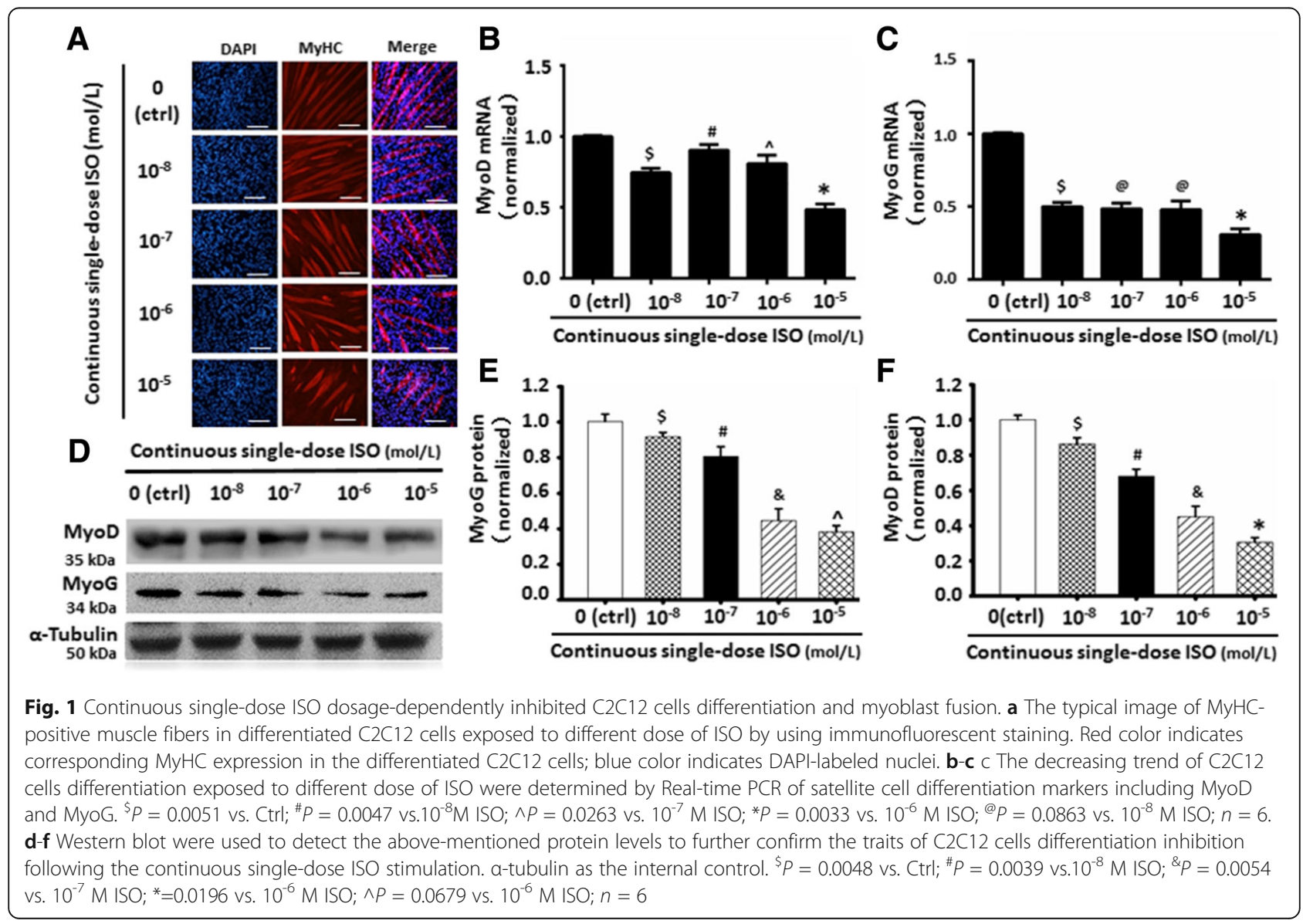


fusion as compared with the transient exposure of ISO. Consistently, less reduction of $\mathrm{MyHC}$ protein level was detected by western blot in ISO-transiently treated cells compared to the ISO-continuously treated cells (Additional file 1: Figure S1D-F). These results suggested that the inhibition to $\mathrm{C} 2 \mathrm{C} 12$ cell differentiation and myotube formation by continuous stimulation of ISO was stronger than the transient stimulation.

To further observe the dose-dependent effect of ISO with continuous exposure on $\mathrm{C} 2 \mathrm{C} 12$ cell differentiation and myoblast fusion, $10^{-8}, 10^{-7}, 10^{-6}$, or $10^{-5} \mathrm{~mol} / \mathrm{L}$ of ISO was used to treat the cells. As shown in Fig. 1, the number and length of MyHC-positive myotubes were dosage-dependently reduced with continuous ISO stimulation. Moreover, continuous stimulation of ISO reduced the myoblast fusion competence (Additional file 1: Figure S2). In line with the myotube morphology, the mRNA and protein expression of satellite cell differentiation markers MyoD (Fig. 1b, d, f) and MyoG (Fig. 1c-e) were dose-dependently decreased while the myotube atrophy marker MuRF1 was induced (Additional file 1: Figure S3). Meanwhile, continuous single-dose ISO time-dependently delayed $\mathrm{C} 2 \mathrm{C} 12$ cell differentiation and myoblast fusion (Fig. 2). These results further demonstrated that continuous single-dose ISO inhibited $\mathrm{C} 2 \mathrm{C} 12$ cell differentiation and myotube formation.

\section{Continuous ISO stimulation altered the muscle fiber types} There are different types of muscle fibers formed by $\mathrm{MyHC1}$ MyHC2a, MyHC2b, or MyHC2X. MyHC1-positive type I fiber shows a slim-long feature. MyHC2a, MyHC2b, and MyHC2X positive type II fiber has thick-short traits $[20,21]$. In line with the reduced myotube formation following continuous ISO stimulation, MyHC1, MyHC2a, MyHC2b, and MyHC2X expression was markedly decreased (Fig. 3a-d). The reduction of MyHC1 (Fig. 3a), MyHC2a (Fig. 3b), and MyHC2X (Fig. 3d) was greater than MyHC2b (Fig. 3c). Although $\mathrm{MyHC1}, \mathrm{MyHC2a}$, and $\mathrm{MyHC} 2 \mathrm{~b}$ were dose-dependently decreased by ISO (Fig. 3a-c), the reduction for MyHC2X remained the same by $10^{-8} \sim 10^{-5} \mathrm{~mol} / \mathrm{L}$ of ISO (Fig. 3d), suggesting a different effect of ISO on different MyHC isoforms. Nevertheless, these results suggested that

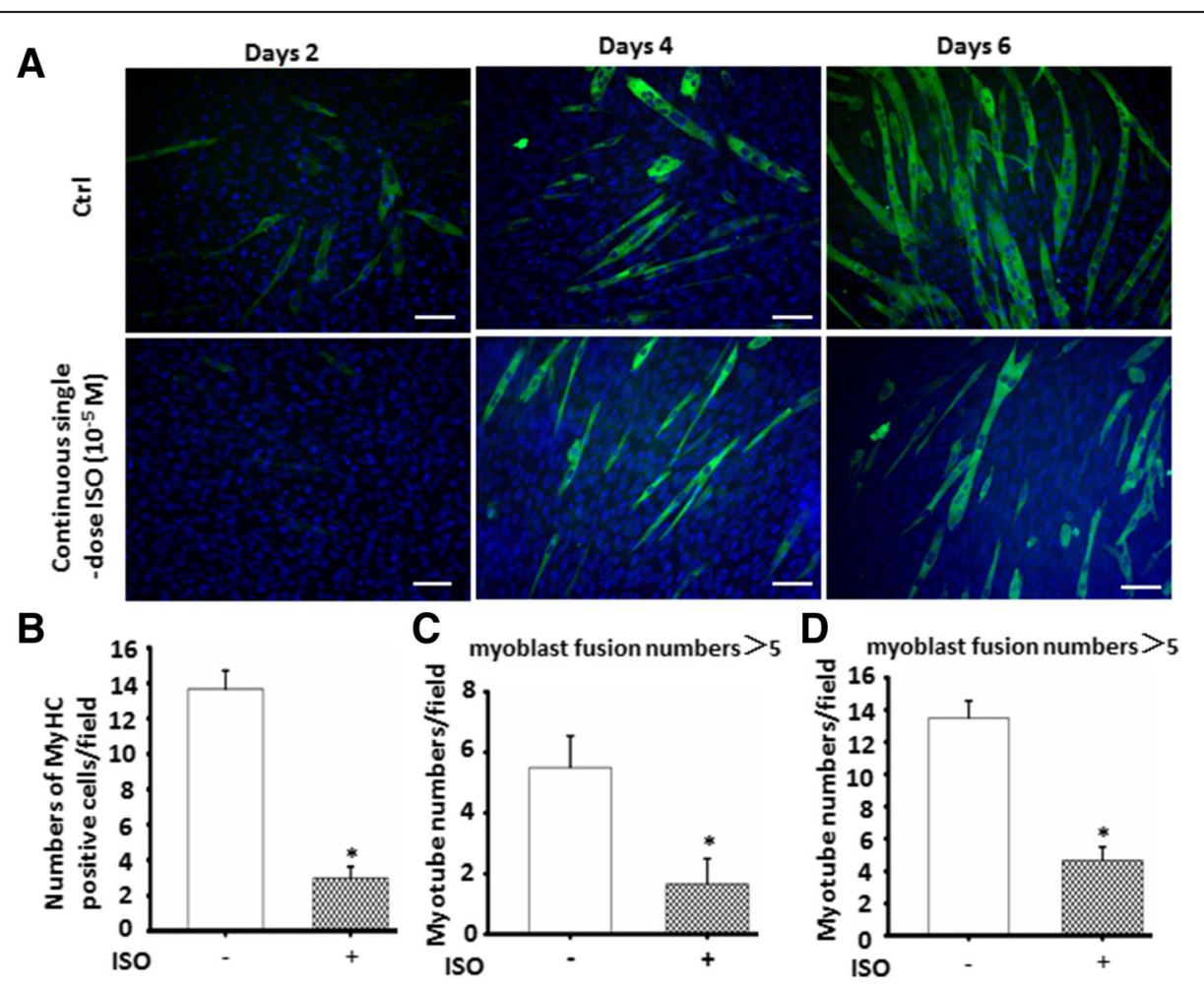

Fig. 2 Continuous single-dose ISO time-dependently delayed C2C12 cells differentiation and myoblast fusion. a The typical image of myoblast fusion day 2, day 4 and day 6 after C2C12 cells differentiation with or without continuous single-dose ISO stimulation as determined by immunofluorescent staining of MyHC. Green color indicates MyHC; blue color indicates DAPI for nuclear labeling. b Continuous single-dose ISO prominently depressed the numbers of MyHC-positive cells day 2 after C2C12 cells differentiation. ${ }^{*} P=0.0000$ vs. Ctrl. c Continuous single-dose ISO remarkably decreased the myotube numbers of more than 5 myoblast fusion day 4 after C2C12 cells differentiation. ${ }^{*} P=0.0000$ vs. Ctrl. d Continuous single-dose ISO markedly reduced the myotube numbers of more than 5 myoblast fusion day 6 after $\mathrm{C} 2 \mathrm{C} 12$ cells differentiation. ${ }^{*} P=0.0000$ vs. Ctrl 

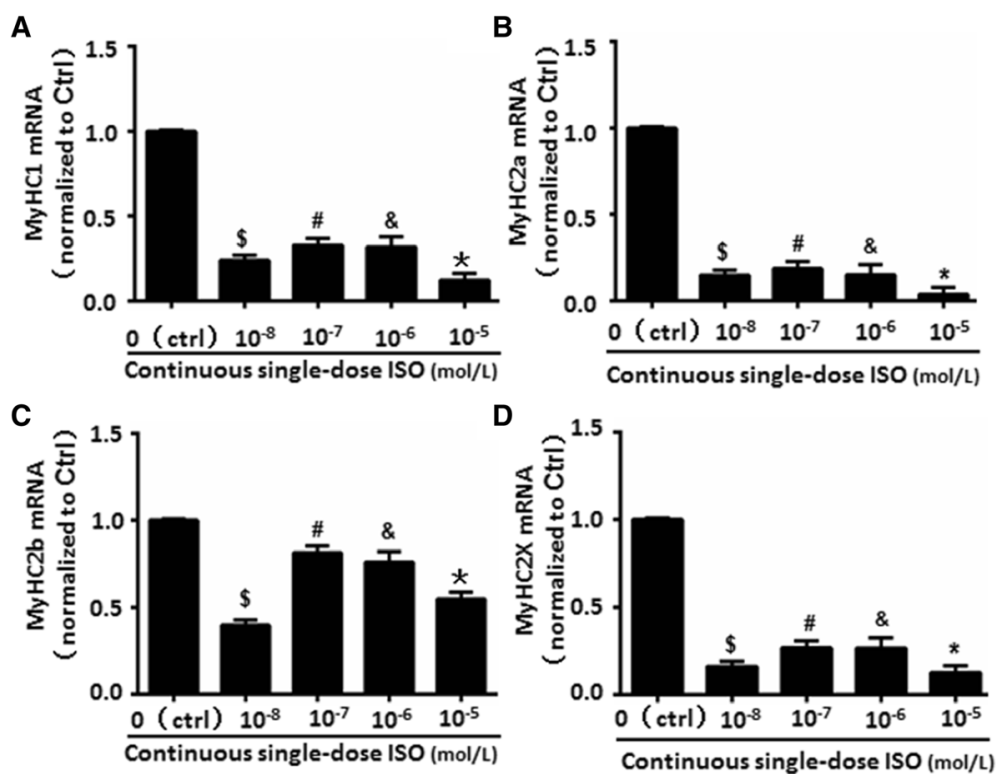

Fig. 3 Continuous single-dose ISO altered the muscle fiber types. a $\mathrm{MyHC1}$, as one of type I muscle fiber maker, were repressed in differentiated C2C12 cells continuously exposed to different doses of ISO by detecting the levels of mRNA using Real-time PCR. $\mathbf{b}$-d Type II muscle fiber makers such as MyHC2a, MyHC2b and MyHC2x have shown the reduced changes of mRNA expressions in differentiated C2C12 cells following continuous single-dose ISO stimulation of mRNA expressions in differentiated C2C12 cells following continuous single-dose ISO stimulation. ${ }^{\$} P=0.0000$ vs. Ctrl; ${ }^{\#} P=0.00368$ vs. $10^{-8} \mathrm{M} \mathrm{ISO} ;{ }^{\&} P=0.0826$ vs. $10^{-7} \mathrm{M} \mathrm{ISO} ;{ }^{*} P=0.0004$ vs. $10^{-6} \mathrm{M} \mathrm{ISO} ; n=6$

continuous ISO stimulation inhibited the expressions of all $\mathrm{MyHC}$ isoforms.

\section{Continuous ISO stimulation delayed $\mathrm{C} 2 \mathrm{C} 12$ cell differentiation and myoblast fusion through altering $\beta$-AdR activities}

In order to explore if continuous single-dose ISO-mediated $\mathrm{C} 2 \mathrm{C} 12$ cell differentiation inhibition is involved in adrenergic receptors (AdRs), $\beta 1$ and $\beta 2$-AdRs in $\mathrm{C} 2 \mathrm{C} 12$ cells were analyzed by using immunofluorescence staining. As shown in Fig. 4a, C2C12 cells expressed $\beta 1-A d R$ and $\beta 2$-AdR. The differentiated $\mathrm{C} 2 \mathrm{C} 12$ cells maintained a $\beta 1$-AdR level similar to the proliferating cells. However, the differentiated $\mathrm{C} 2 \mathrm{C} 12$ cells exhibited a markedly increased $\beta 2$-AdR expression than the proliferating $\mathrm{C} 2 \mathrm{C} 12$ cells (Fig. $4 \mathrm{~b}, \mathrm{c}$ ), indicating that $\beta 2$-AdR could involve in the process of $\mathrm{C} 2 \mathrm{C} 12$ cell differentiation and myoblast fusion.

Since previous studies have shown that the reduced expression and sensitivity of $\beta 2$-AdR in skeletal muscle involved in muscle atrophy during long-term SNS over-activation [8]. As shown in Fig. $4 d-h$, we found that continuous single ISO decreased $\beta 2$-AdR levels while increasing phosphorylated $\beta 2$-AdR (p $\beta 2$-AdR) in differentiated $\mathrm{C} 2 \mathrm{C} 12$ cells, suggesting that the effects of continuous single ISO on delaying $\mathrm{C} 2 \mathrm{C} 12$ cell differentiation and myoblast fusion could involve in inactivation of $\beta 2$-AdR. In addition, continuous single ISO increased $\beta 1$-AdR levels, and $\beta 1$-AdR blocker CPG-20712 A could obviously reverse the inhibitory effects of continuous single ISO on $\mathrm{C} 2 \mathrm{C} 12$ cell differentiation and myoblast fusion. Taken together, continuous ISO stimulation delayed $\mathrm{C} 2 \mathrm{C} 12$ cell differentiation and myoblast fusion through altering $\beta$-AdR activities.

The ratio of PKA RI/RII involved in the inhibitory effect of continuous ISO stimulation on $\mathrm{C} 2 \mathrm{C} 12$ cell differentiation and myoblast fusion

Since ISO exerts its effects by binding to $\beta$-AdR, generally resulting in activation of PKA [8], herein, we detected various subtypes of PKA by using western blot. As shown in Fig. 5a-e and Additional file 1: Figure S4, continuous single-dose ISO did not alter levels of PKA $\alpha$ cat, PKA $\alpha / \beta / \Upsilon$ cat, and PKA $\Upsilon$ cat in C2C12 cells. However, PKA reg II $\alpha$ showed an obvious increase in continuous single-dose ISO-treated $\mathrm{C} 2 \mathrm{C} 12$ cells while decreasing PKA Ri $\alpha$ and PKA RI $\beta$, resulting in a decreased ratio of PKA RI/RII.

To explore if changes of ratio PKA RI/RII were involved in $\mathrm{C} 2 \mathrm{C} 12$ cell differentiation and myoblast fusion, PKA RI agonist $\mathrm{N}^{6}-\mathrm{Bz}-\mathrm{cAMP}$ and PKA inhibitor H-89 were used to confirm the specific effect. As shown in Fig. $5 \mathrm{f}$ and g, PKA RI agonist $\mathrm{N}^{6}$-Bz-cAMP could obviously reverse the inhibitory effects of continuous single-dose ISO on $\mathrm{C} 2 \mathrm{C} 12$ cell differentiation and myoblast fusion. By contrast, PKA inhibitor H-89 further deteriorated the inhibitory effect (Fig. 5f, g). These results indicated that the traits of $\mathrm{C} 2 \mathrm{C} 12$ cell 


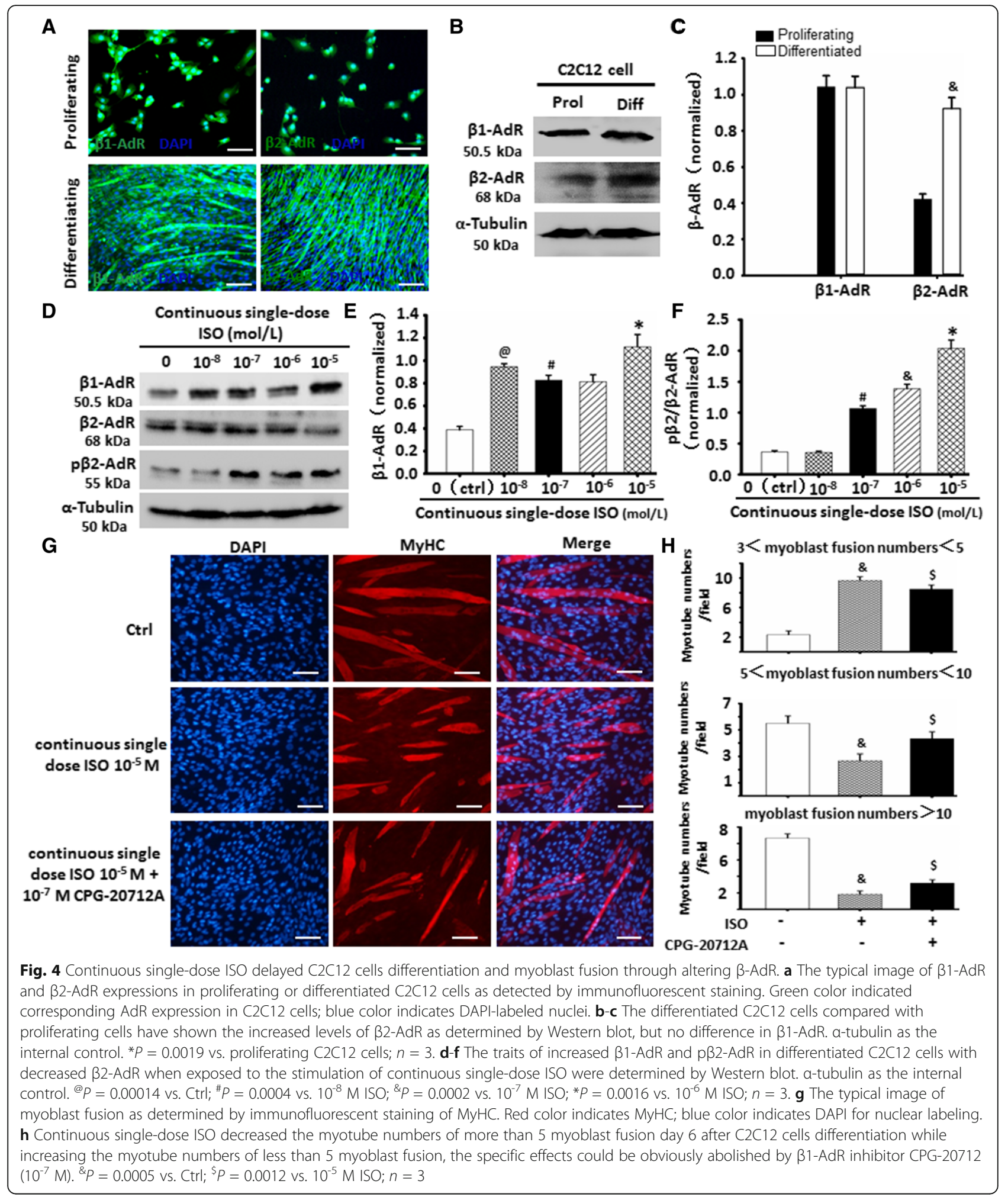

differentiation and myoblast fusion following the stimulation of continuous single-dose ISO could be associated with abnormal changes of ratio of PKA RI/ RII.
The involvement of ERK1/2 in inactivating $\beta 2-A d R$ by continuous single ISO

Previous studies have shown that activated PKC, ERK1/2, and p38MAPK signaling following repeated or long-term 


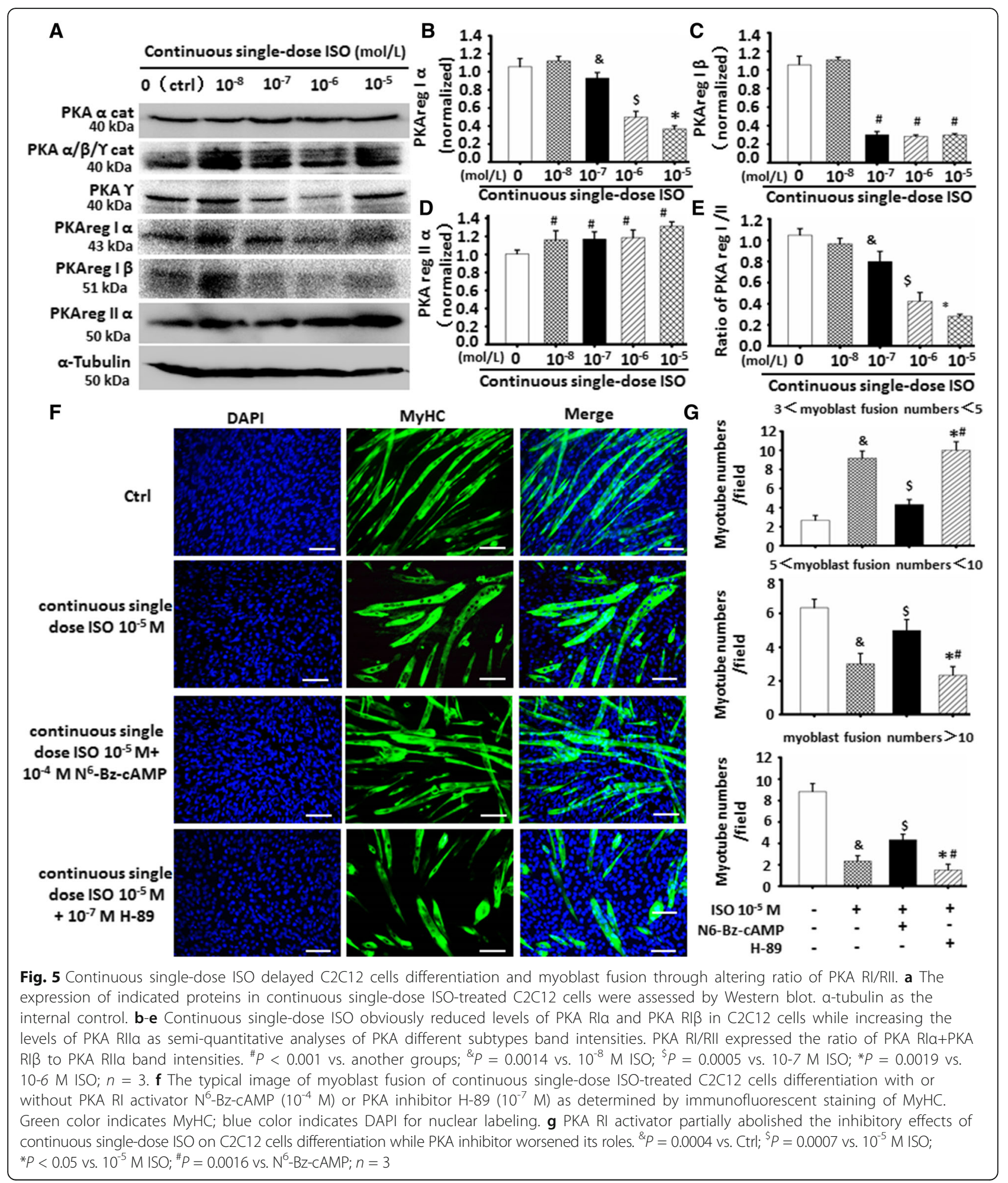

administration of $\beta$-AdR agonist including ISO are involved in the reduced expression and sensitivity of $\beta 2$-AdR, apart from PKA [20-23]. As shown in Fig. 6a, continuous stimulation by ISO did not alter the total PKC, AKT, ERK1/2, and p38MAPK levels in the C2C12 cells. However, it inhibited the activation or phosphorylation of PKC, AKT, and p38MAPK (Fig. 6a-e) while increasing the activation of ERK1/2 (Fig. 6a, c) in a dosage-dependent manner. 


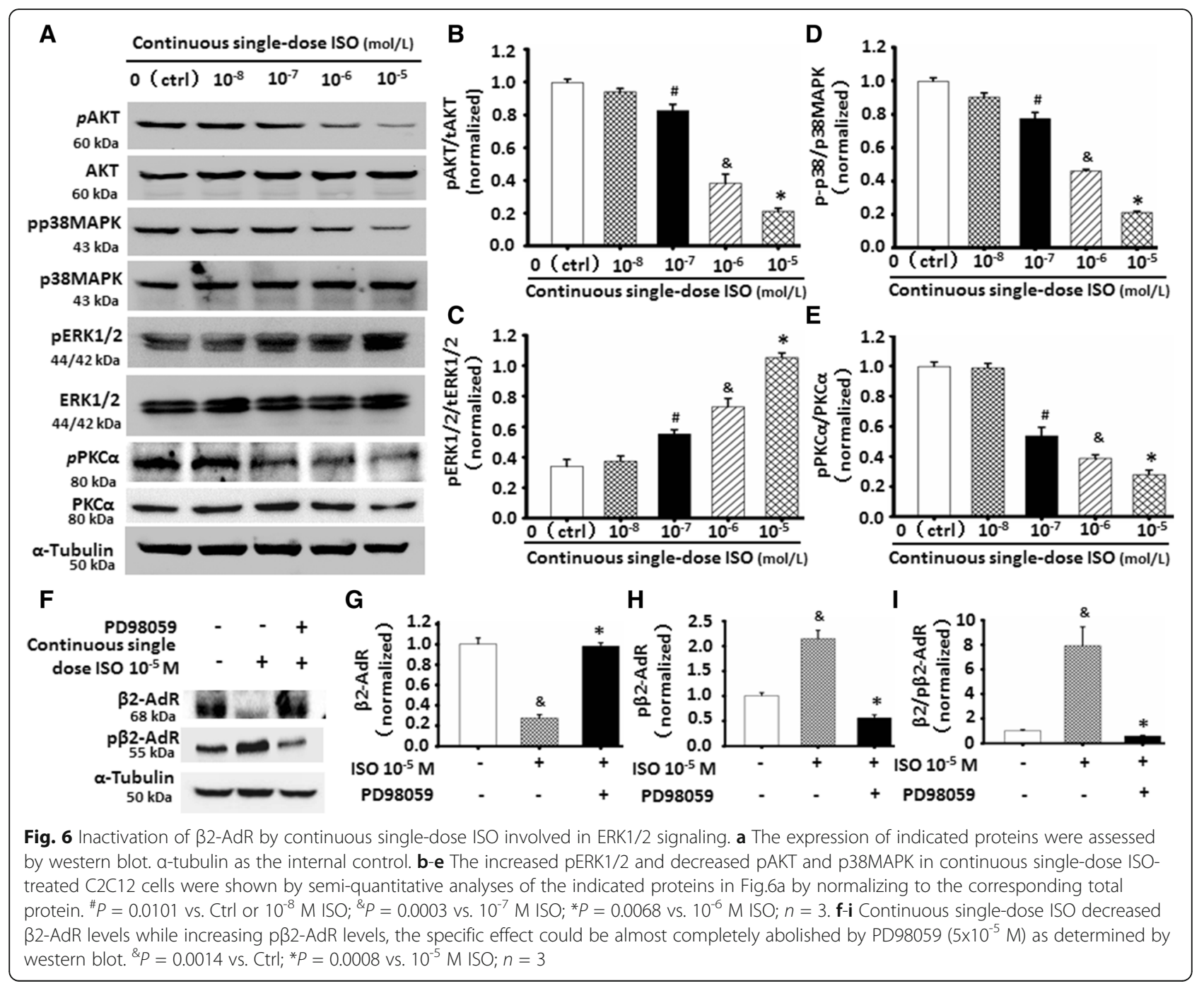

Combining the decreased levels of phosphorylation of $\beta 2-A d R$ ( $p \beta 2-A d R$ ) following the stimulation of continuous single-dose ISO (Fig. 4d-f), these results indicated that activated ERK1/2 signaling could be involved in phosphorylation of $\beta 2$-AdR. Subsequently, ERK1/2 inhibitor PD98059 were used to further confirm if ERK1/2 was involved in the increase of $\mathrm{p} \beta 2$-AdR levels in the ISO-treated $\mathrm{C} 2 \mathrm{C} 12$ cell, the result showed that the special role of continuous single-dose ISO in increasing the levels of $\mathrm{p} \beta 2$-AdRcould be markedly abolished by PD98059 (Fig. 6f-h). Therefore, these data indicated that continuous single ISO-mediated inactivation of $\beta 2$-AdR was involved in ERK1/2 signaling.

\section{ERK1/2-mediated inactivation of $\beta 2$-AdR by ISO involved} in $\mathrm{C} 2 \mathrm{C} 12$ cell differentiation and myoblast fusion

To further determine the role of ERK1/2-mediated inactivation of $\beta 2$-AdR by continuous single-dose ISO in attenuating $\mathrm{C} 2 \mathrm{C} 12$ cell differentiation and myoblast fusion, we firstly observed the expression of MyHC. As shown in Fig. 7a and b, ERK1/2 inhibitor PD98059 could remarkably abolish the inhibitory role in $\mathrm{MyHC}$ expressions. Secondly, immunofluorescence staining of $\mathrm{MyHC}$ was used to evaluate $\mathrm{C} 2 \mathrm{C} 12$ cell differentiation and myoblast fusion (Fig. 7c). Finally, we quantificationally analyzed the changes of myotube morphology. As shown in Fig. 7d-i, PD98059 obviously increased the numbers of myotube with 5 to 10 myoblast fusions (Fig. 7d), coupling with the increased numbers of myotube with a length of 200 to $400 \mu \mathrm{m}$ (Fig. 7h). Combining the results of Fig. 6, ERK1/2 signaling might be involved in the inhibitory effects of continuous single-dose ISO on $\mathrm{C} 2 \mathrm{C} 12$ cell differentiation and myotube formation through inactivating $\beta 2$-AdR.

ERK1/2 involved in $\mathrm{C} 2 \mathrm{C} 12$ cell differentiation and muscle fiber types through FoxO1 signaling

Recent studies have shown that AKT, ERK1/2, and p38MAPK signaling are involved in the regulation of 


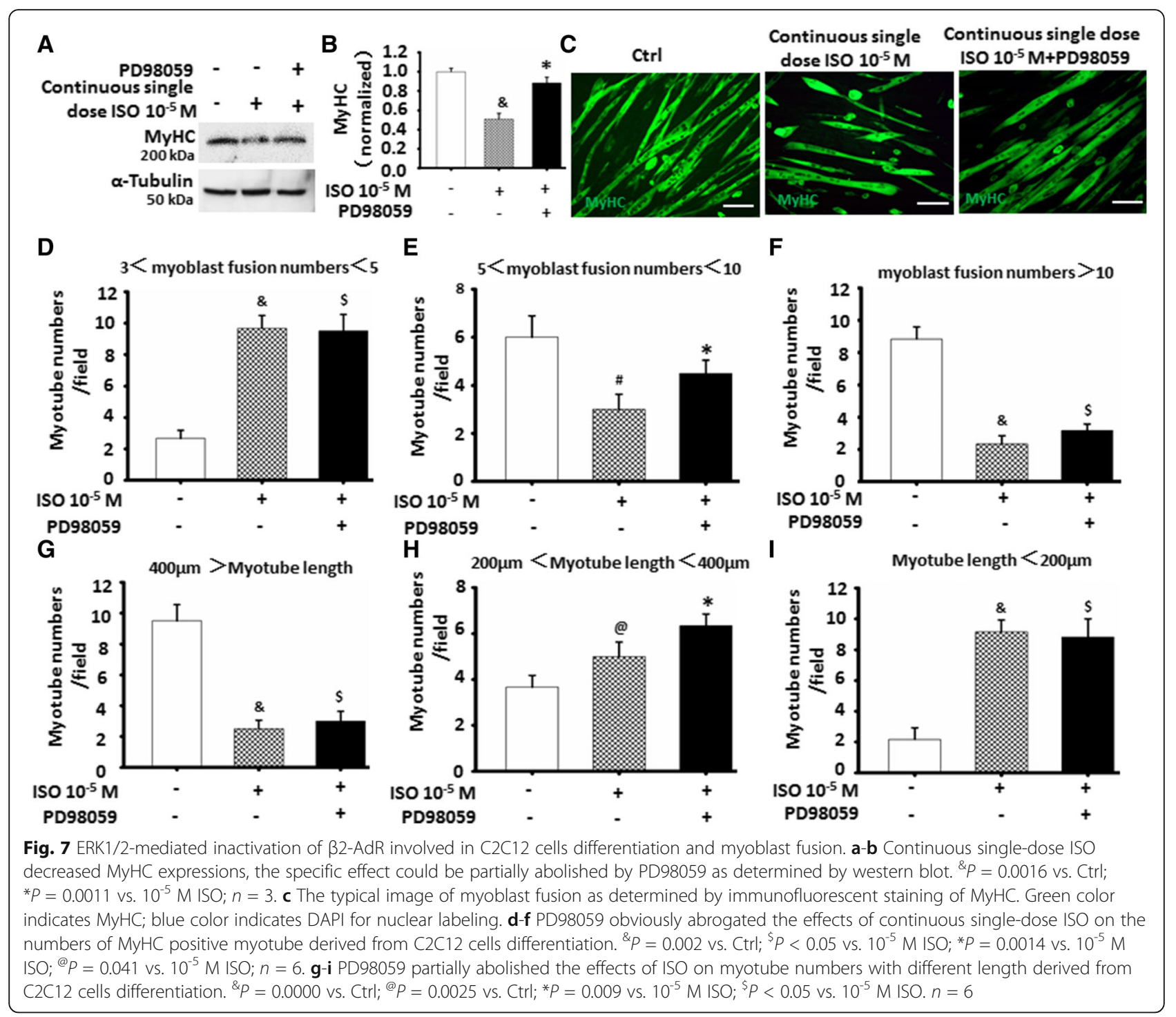

C2C12 cell differentiation and myoblast fusion ([24-26], and). In consistent with the results of Figs. 6 and 7, using real-time PCR to further evaluate the changes of muscle fiber types in continuous single-dose ISO-treated $\mathrm{C} 2 \mathrm{C} 12$ cell, especially in coexistence of ISO with PD98059, we found that PD98059 increased the expression of $\mathrm{MyHC1}$ and $\mathrm{MyHC2a}$ while decreasing the expression of MyHC2b and MyHC2X (Fig. 8a-d) as compared with the ISO-treated group, indicating ERK/1/2 was important for the formation of myotube.

FOXO1, a downstream target of AKT and p38 MAPK $[27,28]$, plays a crucial role in muscle satellite cell differentiation and myoblast fusion, especially in I type fiber differentiation $[29,30]$. In line with the decreased levels of pAKT and p-p38 MAPK in Fig. 6, as shown in Additional file 1: Figure S3, continuous stimulation by ISO gradually decreased the levels of
FOXO1phosphorylation in $\mathrm{C} 2 \mathrm{C} 12$ cell cytoplasm, leading to the increase of nuclear FOXO1 levels (Fig. 8e-i), indicating that highly activated FOXO1 is involved in the inhibition of myotube formation. Accompanied by the partial recovery of pAKT and p-p38 MAPK levels in the ISO-treated $\mathrm{C} 2 \mathrm{C} 12$ cells, PD98059 decreased the levels of nuclear FOXO1 (Fig. 8h, i). Meanwhile, a significantly more nuclear translocation of FOXO1 was observed in the cells with continuous ISO stimulation as compared to the normally differentiated cells as shown by the double immunostaining of MyHC and FOXO1 (Fig. 8j). Furthermore, PD98059 partially recovered the nuclear translocation of FOXO1, in similar to normal state of differentiated $\mathrm{C} 2 \mathrm{C} 12$ cells. Taken together, these data suggested that FOXO1 activation by ISO correlated with $\mathrm{C} 2 \mathrm{C} 12$ cell differentiation and myoblast fusion, which was associated with ERK1/2 signaling. 


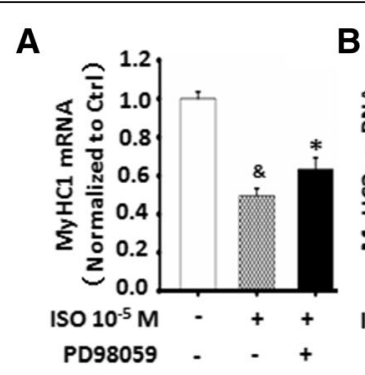

E
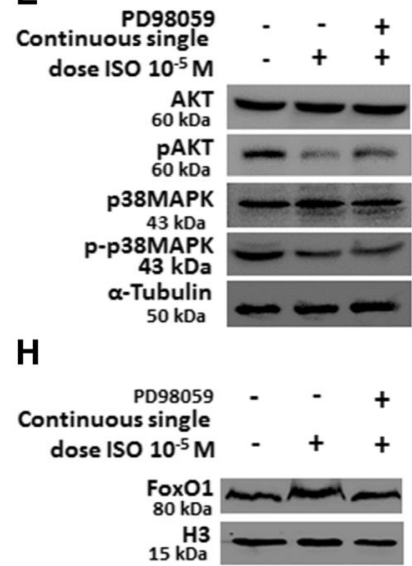

I

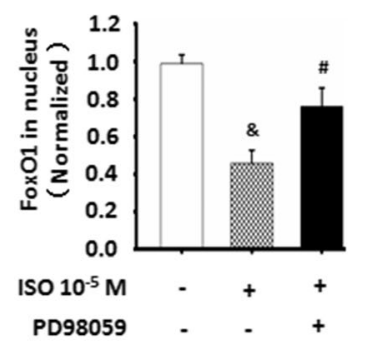

B C

C D

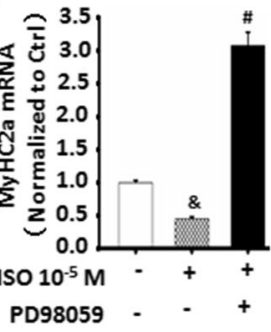

F

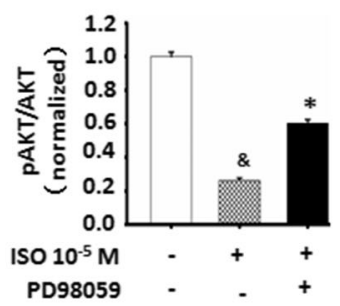

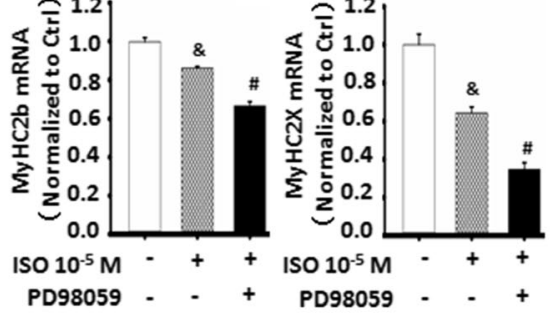

G

Continuous single dose Continuous single dose

J Ctrl

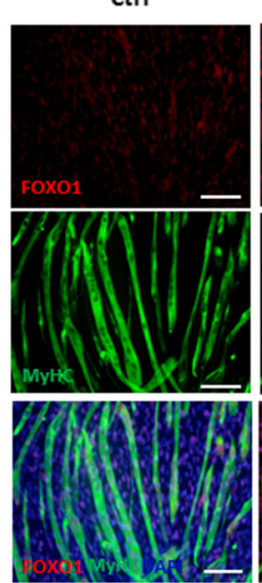
ISO $10^{-5} \mathrm{M}$
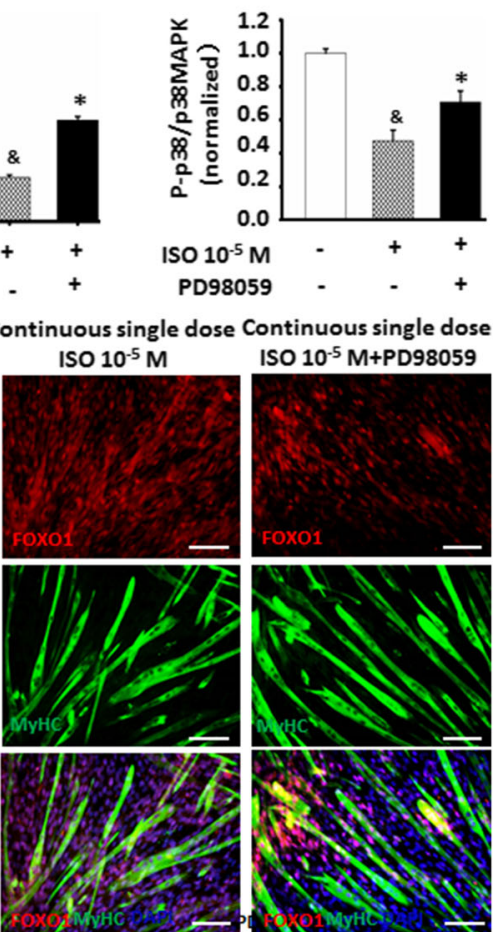

ISO $10^{-5} \mathrm{M}+\mathrm{PD} 98059$

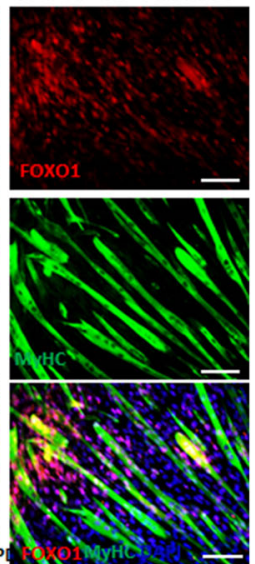

Fig. 8 ERK1/2 involved in C2C12 cells differentiation and muscle fiber types through FoxO1 signaling. a-d ERK1/2 inhibitor PD98059 partially abrogated the role of continuous single-dose ISO in repressing the expression of MyHC1 and MyHC2a as detected by Real-time PCR, in addition to further reducing the mRNA levels of MyHC2b and MyHC2x. ${ }^{\&} P=0.0000$ vs. Ctrl; ${ }^{*} P=0.0292$ vs. $10^{-5} \mathrm{M} \mathrm{ISO} ;{ }^{\#} P=0.0004$ vs. Ctrl; $n=6$. e-g PD98059 in part recovered the decreased levels of pAKT, and p-p38MAPK in ISO-treated C2C12 cells as determined by Western blot and band intensities. a-tubulin as the internal control. ${ }^{\&} P=0.0004$ vs. Ctrl; ${ }^{*} P=0.0122$ vs. $10^{-5} \mathrm{M} \mathrm{ISO} n=3$. h-i ERK1/2 inhibitor PD98059 partially decreased the levels of nuclear FOXO1 in continuous single-dose ISO-treated C2C12 cells as analyzed by Western blot band intensities. ${ }^{\circledR} P=0.0004$ vs. Ctrl; $\# P=0.0124$ vs. $10^{-5} \mathrm{M}$ ISO; $n=3$. j ERK1/2 inhibitor PD98059 partially reduced nuclear translocation of FOXO1 in differentiated C2C12 cells induced by ISO as detected by immunofluorescent staining. Red: FOXO1; green: MyHC; blue: DAPI-labeled nuclei

\section{Discussion}

Due to hyperexcitability of SNS, the damage triggered by the increased levels of $\mathrm{NE}$ and $\mathrm{E}$ often attributes to the activation of $\beta$-AdR [7]. Since NE and E can bind to both the $\alpha$-AdR and $\beta$-AdR, causing difficulty to analyze the unique role of each subtype of AdRs [2], a more stable $\beta$-AdR-binding isoproterenol (ISO) has been used to mimic the effect of $\beta$-AdR activation. In previous studies, transient stimulation with a single high dose of ISO $\left(10^{-4} \mathrm{M}\right)$ is used to induce skeletal muscle atrophy $[31,32]$. In this study, we established a clinically relevant chronic activation of $\beta$-AdR, i.e., continuous stimulation with ISO, to observe its effect on $\mathrm{C} 2 \mathrm{C} 12$ cell differentiation and myoblast fusion. Our studies made three novel observations. Firstly, activation of $\beta 1$-AdR and inactivation of $\beta 2$-AdR by continuous ISO stimulation contributed to the decreased ratio of PKA RI/RII, causing a greater inhibition of $\mathrm{C} 2 \mathrm{C} 12$ cell differentiation and myoblast fusion. Secondly, continuous ISO stimulation desensitized $\beta 2$-AdR by activating ERK1/2 signaling. And lastly, continuous stimulation of ISO inhibited $\mathrm{C} 2 \mathrm{C} 12$ cell differentiation and myoblast fusion, leading to the decrease of type I and type II myotube formation, at least in part, by activating the ERK1/2-FOXO1 signaling. 
Traditionally, the stimulated AdRs have been thought to couple with the PKA activation mediated by G-protein/AC. Stimulation of this pathway has been linked to myoblast differentiation and myotube formation, attributing to the activation of PKA RI during physiological condition [33]. In continuous ISO stimulation system, as a typical simulation model in vitro for excessive SNS-associated pathological state in vivo, we found that it decreased the levels of both PKA RI $\alpha$ and RI $\beta$ while increasing PKA RII $\alpha$ levels, resulting in delaying $\mathrm{C} 2 \mathrm{C} 12$ cell differentiation and reducing myotube formation. Further evidences have shown that continuous ISO stimulation increased $\beta 1$-AdR expression while decreasing $\beta 2$-AdR levels linked to the levels of $\mathrm{p} \beta 2$-AdR, which were associated with activation of ERK1/2 signaling. Our studies have demonstrated $\beta 1$-AdR antagonist CPG-20712A partially abolish the inhibitory effect of ISO on $\mathrm{C} 2 \mathrm{C} 12$ differentiation and myoblast fusion. Recent reports have shown that $\beta 2$-AdR agonists including clenbuterol or fenoterol increased skeletal muscle mass [34, 35]. And ERK1/2 inhibitor PD98059 recovered the levels of $\beta 2$-AdR, leading to the recovery of $\mathrm{C} 2 \mathrm{C} 12$ differentiation and myoblast fusion, consistent with its role in restoring the differentiation potential of Ras-transformed C2C12 myoblasts [36]. Therefore, the changes of ERK1/ 2 -mediated $\beta$-AdR activities induced by continuous ISO stimulation could cause the alteration of ratio of PKA RI/RII, triggering the abnormal myoblast differentiation and myotube fusion.

As a result of phosphorylation, inactivation of $\beta 2$-AdR was frequently controlled by PKA, PKC, p38MAPK, ERK1/2, and G-protein-coupled receptor kinases (GRKs) [37-39]. In the present study, accompanied by increased $\mathrm{p} \beta 2$-AdR levels, $\beta 2$-AdR levels were remarkably decreased in $\mathrm{C} 2 \mathrm{C} 12$ cells following continuous ISO stimulation, attributing to the activation of ERK $1 / 2$. Indeed, previous studies have shown that $\mathrm{pERK} 1 / 2$ could accelerate $\beta 2$-AdR desensitization through the process of catalyzing the hydrolysis of cAMP into AMP by inducing the expression of phosphodiesterase 4 (PDE4) mediated by the activated CREB (cAMP response element binding protein), apart from triggering GRK4 to phosphorylate $\beta 2$-AdR [40-42]. Of interest, continuous single-dose ISO-treated $\mathrm{C} 2 \mathrm{C} 12$ cells showed the unique characteristics of active separation of both $\beta 1$-AdR and $\beta 2-A d R$, indicating that other unknown mechanisms could involve this particular phenomenon, which could be further explored in the future.

Published data have shown that FOXO1 play a crucial role in myotube formation, especially type I myotube formation $[29,30]$. FOXO1 activities are frequently regulated by PI3K/AKT and p38MAPK pathway during C2C12 cell differentiation [24-26]. Herein, we found that continuous ISO stimulation decreased the levels of pAKT while increasing the pERK1/2 levels, resulting in more FOXO1 levels. Conversely, ERK1/2 inhibitor PD98059, at least in part, through recovering the levels of pAKT and p-p38MAPK, reduced nuclear translocation of FOXO1 and the levels of nuclei FOXO1in $\mathrm{C} 2 \mathrm{C} 12$ cells, contributing to the partial recovery of $\mathrm{C} 2 \mathrm{C} 12$ cell differentiation and myotube formation, mainly in type II myotube formation. Of interest, a constitutively active FOXO1 mutation at the AKT phosphorylation site inhibits $\mathrm{C} 2 \mathrm{C} 12$ cell differentiation and type I myotube formation [29, 30]. Since continuous ISO stimulation inhibits the formation of both type I and II myotubes, factors other than FOXO1 may also be involved in $\mathrm{C} 2 \mathrm{C} 12$ cell differentiation and fusion, which could be studied in the future.

One limitation of this study is the lack of in vivo evidence that the excessive SNS-muscular dystrophy is involved in dysfunction of skeletal muscle satellite cells and corresponding abnormal signal pathways. In the future, we could use Duchenne and Becker muscular dystrophy and/or long-term sympathetic nerve hyperactivity models to analyze muscle satellite cell function and signaling pathways involved, and test if continuous stimulation with ISO inhibits satellite cell and myoblast fusion. These in vivo studies may ultimately provide strategies to treat MD through correcting the autonomic imbalance or controlling the signaling involved.

\section{Conclusion}

Continuous stimulation with ISO appears to be a valuable model for studying the excessive SNS-associated muscle satellite cell function. Our results reveal a novel mechanism underlying the ISO inhibition in C2C12 cell differentiation and myoblast fusion, i.e., ISO binds to AdR, which alters the ratio of PKA RI/RII and activates ERK1/2 while inhibiting PKC, AKT, and p38MAPK signaling, leading to over-activation of FOXO1, thus inhibiting $\mathrm{C} 2 \mathrm{C} 12$ cell differentiation and myotube formation.

\section{Additional file}

Additional file 1: Figure S1. Continuous single-dose ISO obviously inhibited $\mathrm{C} 2 \mathrm{C} 12$ cell differentiation and myoblast fusion than single-dose ISO. Figure S2. Continuous ISO stimulation altered myoblast fusion competence of myotube during C2C12 cell differentiation. Figure S3. Continuous single ISO involved in C2C12 cell differentiation and muscle fiber types through FoxO1 signaling. Figure S4. Continuous single ISO did not alter levels of PKA a cat, PKA a/ $\beta / Y$ cat, PKA Y cat in C2C12 cell differentiation. (DOCX 519 kb)

\footnotetext{
Abbreviations

AC: Adenylate cyclase; AdR: Adrenergic receptor; AKT: Protein Kinase B: DAPI: 4',6-Diamidino-2-Pheny lindole; DCM: Dilated cardiomyopathy; DMEM: Dulbecco's modified Eagle's medium; E: Epinephrine; ERK1/ 2: Extracellular signal-regulated kinase1/2; FBS: Fetal bovine serum; FOXO1: Forkhead box protein O1; HF: Heart failure; HRP: Horseradish peroxidase; HS: Horse serum; IF: Immunofluorescence; IGF-1: Insulin-like growth factor; ISO: Isoprenaline; M: MoI/L; MAPK: Mitogen-activated protein kinase; MD: Muscular dystrophy; MuRF1: Muscle-specific RING-finger protein 1; MyHC: Myosin heavy chain; MyHC1: Myosin heavy chain 1; MyHC2a: Myosin heavy chain 2a; MyHC2b: Myosin heavy chain 2b; MyHC2x: Myosin heavy chain 2x; MyoD: Myogenic differentiation 1;
} 
MyoG: Myogenin; NE: Norepinephrine; PBS: Phosphate buffered saline; PKA Rlla: PKA regulatory subunit Ila; PKA RII $\beta$ : PKA regulatory subunit I $\beta$; PKA Rla: PKA regulatory subunit la; PKA RI $\beta$ : PKA regulatory subunit $1 \beta ;$ PKA $a / \beta / \gamma$ cat: PKA $a / \beta / \gamma$ catalytic subunits; PKA: Protein kinase A; PKAa cat: PKA alpha catalytic subunit; PKA 3 cat: PKA beta catalytic subunit; PKC: Protein Kinase C; PVDF: Polyvinylidene fluoride; qPCR: Quantitative polymerase chain reaction; SNS: Sympathetic nerve system

\section{Acknowledgements}

Not applicable.

\section{Funding}

This study was supported by grants from the National Natural Science Foundation of China $(81670272,81170095$ to J.M.T), Hubei Science\& Technology Department Foundation (2018ACA162, 2016CFA027 to J.M.T), Hubei University of Medicine Innovation Team (FDFR201601 to J.M.T).

\section{Availability of data and materials}

Please contact corresponding author for data requests.

\section{Authors' contributions}

SJC and JY carried out the main cells' experimental and drafted the manuscript. LX carried out $\mathrm{QPCR}$, protein detection, and immunostaining. MJ carried out the cell cultures. TQH and WDL carried out the data evaluation. XYL participated in the immunostaining. $L Z, F Z$, and $Y Y$ participated in protein assay. $L Y G, Y M P$, and YWY participated in the myotube analysis. JNW participated in the design of the study and performed the statistical analysis. SYC helped to draft and revise the manuscript. JXZ performed the protein detection and participated in the revision of manuscript. JMT conceived of the study, participated in the experimental design and coordination of the study, and helped to draft the manuscript. All authors read and approved the final manuscript.

\section{Ethics approval and consent to participate}

Not applicable.

\section{Consent for publication}

Not applicable.

\section{Competing interests}

The authors declare that they have no competing interests.

\section{Publisher's Note}

Springer Nature remains neutral with regard to jurisdictional claims in published maps and institutional affiliations.

\section{Author details}

'Department of Cardiology, and Institute of Clinical Medicine, Renmin Hospital, Hubei University of Medicine, Shiyan 442000, Hubei, People's Republic of China. ${ }^{2}$ Department of Stomatology, Taihe Hospital, Hubei University of Medicine, Shiyan 442000, Hubei, People's Republic of China. ${ }^{3}$ Department of Physiology, School of Basic Medical Sciences, Hubei University of Medicine, Shiyan 442000, Hubei, People's Republic of China. ${ }^{4}$ Department of Stomatology, Renmin Hospital, Hubei University of Medicine, Shiyan 442000, Hubei, People's Republic of China. ${ }^{5}$ Institute of biomedicine and Key Lab of Human Embryonic Stem Cell of Hubei Province, Hubei University of Medicine, Shiyan 442000, Hubei, People's Republic of China. ${ }^{6}$ Department of Physiology \& Pharmacology, The University of Georgia, Athens GA30602, USA.

Received: 23 December 2018 Revised: 25 January 2019 Accepted: 30 January 2019 Published online: 28 February 2019

\section{References}

1. Smith SA, Downey RM, Williamson JW, Mizuno M. Autonomic dysfunction in muscular dystrophy: a theoretical framework for muscle reflex involvement. Front Physiol. 2014;5:47.

2. Li Y, Zhang S, Zhang $X$, et al. Blunted cardiac beta-adrenergic response as an early indication of cardiac dysfunction in Duchenne muscular dystrophy. Cardiovasc Res. 2014;103(1):60-71.
3. Triposkiadis F, Karayannis G, Giamouzis G, Skoularigis J, Louridas G, Butler J. The sympathetic nervous system in heart failure physiology, pathophysiology, and clinical implications. J Am Coll Cardiol. 2009;54(19):1747-62.

4. Brum PC, Bacurau AV, Cunha TF, et al. Skeletal myopathy in heart failure: effects of aerobic exercise training. Exp Physiol. 2014;99(4):616-20.

5. Lymperopoulos A, Rengo G, Koch WJ. Adrenergic nervous system in heart failure: pathophysiology and therapy. Circ Res. 2013;113(6):739-53.

6. Florea VG, Cohn JN. The autonomic nervous system and heart failure. Circ Res. 2014;114(11):1815-26.

7. Bacurau AV, Jardim MA, Ferreira JC, et al. Sympathetic hyperactivity differentially affects skeletal muscle mass in developing heart failure: role of exercise training. J Appl Physiol. 2009;106(5):1631-40.

8. Voltarelli VA, Bechara LR, Bacurau AV, et al. Lack of $\beta 2$-adrenoceptors aggravates heart failure-induced skeletal muscle myopathy in mice. J Cell Mol Med. 2014;18(6):1087-97.

9. André LM, Ausems CRM, Wansink DG, et al. Abnormalities in skeletal muscle myogenesis, growth, and regeneration in myotonic dystrophy. Front Neurol. 2018;9:368.

10. Thornell LE, Lindstöm M, Renault $V$, et al. Satellite cell dysfunction contributes to the progressive muscle atrophy in myotonic dystrophy type 1. Neuropathol Appl Neurobiol. 2009;35(6):603-13.

11. Pelletier R, Hamel F, Beaulieu D, et al. Absence of a differentiation defect in muscle satellite cells from DM2 patients. Neurobiol Dis. 2009;36(1):181-90.

12. Chen SJ, Li X, Jiang M, et al. Isoprenaline induced muscle atrophy by inhibiting C2C12 cell differentiation into skeletal muscle cells. Chin J Cell Biol. 2017:9:1178-87.

13. Tang JM, Luo B, Xiao JH, et al. VEGF-A promotes cardiac stem cell engraftment and myocardial repair in the infarcted heart. Int J Cardiol. 2015;183:221-31.

14. Ross JA, Levy Y, Svensson K, et al. SIRT1 regulates nuclear number and domain size in skeletal muscle fibers. J Cell Physiol. 2018;233(9):7157-716.

15. Hicks MR, Cao TV, Standley PR. Biomechanical strain vehicles for fibroblastdirected skeletal myoblast differentiation and myotube functionality in a novel coculture. Am J Physiol Cell Physiol. 2014;307(8):C671-83.

16. Millay DP, O'Rourke JR, Sutherland LB, et al. Myomaker is a membrane activator of myoblast fusion and muscle formation. Nature. 2013;499(7458):301-5.

17. Hughes DC, Stewart CE, Sculthorpe N, et al. Testosterone enables growth and hypertrophy in fusion impaired myoblasts that display myotube atrophy: deciphering the role of androgen and IGF-I receptors. Biogerontology. 2016;17(3):619-39.

18. Chen X, Wan J, Yu B, et al. PIP5K1 a promotes myogenic differentiation via AKT activation and calcium release. Stem Cell Res Ther. 2018;9(1):33.

19. Li GH, Luo B, Lv YX, et al. Dual effects of VEGF-B on activating cardiomyocytes and cardiac stem cells to protect the heart against short- and long-term ischemia-reperfusion injury. JTransl Med. 2016;14(1):116.

20. Hausdorff WP, Caron MG, Lefkowitz RJ. Turning off the signal: desensitization of beta-adrenergic receptor function. FASEB J. 1990;4(11):2881-9.

21. Pitcher J, Lohse MJ, Codina J, Caron MG, Lefkowitz RJ. Desensitization of the isolated beta 2-adrenergic receptor by beta-adrenergic receptor kinase, cAMP-dependent protein kinase, and protein kinase C occurs via distinct molecular mechanisms. Biochemistry. 1992;31(12):3193-7.

22. Lefkowitz RJ, Shenoy SK. Transduction of receptor signals by beta-arrestins. Science. 2005;308(5721):512-7.

23. Peregrin S, Jurado-Pueyo M, Campos PM, Sanz-Moreno V, Ruiz-Gomez A, Crespo P, Mayor F Jr. MurgaC.Phosphorylation of p38 by GRK2 at the docking groove unveils a novel mechanism for inactivating p38MAPK. Curr Biol. 2006;16(20):2042-7.

24. Lee SJ, Hwang J, Jeong HJ, et al. PKN2 and Cdo interact to activate AKT and promote myoblast differentiation. Cell Death Dis. 2016;7(10):e2431.

25. Garcia-Guerra L, Vila-Bedmar R, Carrasco-Rando M, et al. Skeletal muscle myogenesis is regulated by $\mathrm{G}$ protein-coupled receptor kinase 2. J Mol Cell Biol. 2014;6(4):299-311.

26. Tran P, Ho SM, Kim BG, et al. TGF- $\beta$-activated kinase 1 (TAK1) and apoptosis signal-regulating kinase 1 (ASK1) interact with the promyogenic receptor Cdo to promote myogenic differentiation via activation of p38MAPK pathway. J Biol Chem. 2012;287(15):11602-15.

27. Martín Al, Gómez-SanMiguel AB, Gómez-Moreira C, et al. aMSH blunts endotoxin-induced MuRF1 and atrogin-1 upregulation in skeletal muscle by modulating NF-KB and AKT/FoxO1 pathway. Mediat Inflamm. 2014;2014: 179368.

28. De Alvaro C, Nieto-Vazquez I, Rojas JM, et al. Nuclear exclusion of forkhead box $\mathrm{O}$ and Elk1 and activation of nuclear factor-kappaB are required 
for C2C12-RasV12C40 myoblast differentiation. Endocrinology. 2008;149(2):793-801.

29. Kitamura T, Kitamura YI, Funahashi Y, et al. A FoxO/Notch pathway controls myogenic differentiation and fiber type specification. J Clin Invest. 2007;117(9):2477-85.

30. Yuan Y, Shi XE, Liu YG, et al. FoxO1 regulates muscle fiber-type specification and inhibits calcineurin signaling during $\mathrm{C} 2 \mathrm{C} 12$ myoblast differentiation. Mol Cell Biochem. 2011;348(1-2):77-87.

31. Martinez PF, Okoshi K, Zornoff LA, et al. Chronic heart failure-induced skeletal muscle atrophy, necrosis, and changes in myogenic regulatory factors. Med Sci Monit. 2010;16(12):BR374-83.

32. Burniston JG, Tan LB, Goldspink DF. Beta2-adrenergic receptor stimulation in vivo induces apoptosis in the rat heart and soleus muscle. J Appl Physiol. 2005;98(4):1379-86.

33. Han SY, Park DY, Lee GH, Park SD, Hong SH. Involvement of type I protein kinase $\mathrm{A}$ in the differentiation of $\mathrm{L} 6$ myoblast in conjunction with phosphatidylinositol 3-kinase. Mol Cells. 2002;14(1):68-74.

34. Lynch GS, Ryall JG. Role of beta-adrenoceptor signaling in skeletal muscle: implications for muscle wasting and disease. Physiol Rev. 2008:88(2):729-67.

35. Sneddon AA, Delday MI, Maltin CA. Amelioration of denervation-induced atrophy by clenbuterol is associated with increased PKC-alpha activity. Am J Physiol Endocrinol Metab. 2000;279(1):E188-95.

36. Conejo R, de Alvaro C, Benito M, et al. Insulin restores differentiation of Ras-transformed C2C12 myoblasts by inducing NF-kappaB through an AKT/P70S6K/p38-MAPK pathway. Oncogene. 2002;21(23):3739-53.

37. Vaughan DJ, Millman EE, Godines V, Friedman J, Tran TM, Dai W, Knoll BJ, Clark RB, Moore RH. Role of the G protein-coupled receptor kinase site serine cluster in beta2-adrenergic receptor internalization, desensitization, and beta-arrestin translocation. J Biol Chem. 2006;281 (11):7684-92.

38. Cassier E, Gallay N, Bourquard T, Claeysen S, Bockaert J, Crépieux P, Poupon A, Reiter E, Marin P. VandermoereF.Phosphorylation of $\beta$-arrestin2 at Thr383 by MEK underlies $\beta$-arrestin-dependent activation of Erk1/2 by GPCRs. Elife. 2017:6:e23777.

39. Sallese M, lacovelli L, Cumashi A, Capobianco L, Cuomo L, De Blasi A. Regulation of $\mathrm{G}$ protein-coupled receptor kinase subtypes by calcium sensor proteins. Biochim Biophys Acta. 2000;1498(2-3):112-21.

40. Shi Q, Li M, Mika D, Fu Q, Kim S, Phan J, Shen A, Vandecasteele G, Xiang YK Heterologous desensitization of cardiac $\beta$-adrenergic signal via hormone-induced BAR/arrestin/PDE4 complexes. Cardiovasc Res. 2017:113(6):656-70.

41. Hu A, Nino G, Grunstein JS, Fatma S, Grunstein MM. Prolonged heterologous beta2-adrenoceptor desensitization promotes proasthmatic airway smooth muscle function via PKA/ERK1/2-mediated phosphodiesterase-4 induction. Am J Physiol Lung Cell Mol Physiol. 2008;294(6):L1055-67.

42. Nino G, Hu A, Grunstein JS. GrunsteinMM.Mechanism regulating proasthmatic effects of prolonged homologous beta2-adrenergic receptor desensitization in airway smooth muscle. Am J Physiol Lung Cell Mol Physiol. 2009;297(4):L746-57.

Ready to submit your research? Choose BMC and benefit from:

- fast, convenient online submission

- thorough peer review by experienced researchers in your field

- rapid publication on acceptance

- support for research data, including large and complex data types

- gold Open Access which fosters wider collaboration and increased citations

- maximum visibility for your research: over $100 \mathrm{M}$ website views per year

At $\mathrm{BMC}$, research is always in progress.

Learn more biomedcentral.com/submissions 